\title{
Non-Enhancing Lesion
}

National Cancer Institute

\section{Source}

National Cancer Institute. Non-Enhancing Lesion. NCI Thesaurus. Code C81175.

Visibly abnormal tissue on a magnetic resonance image (MRI) or computed tomography (CT) that does not enhance with contrast and is not edema. 